\title{
The usefulness of wide excision assisted by a computer navigation system and reconstruction using a frozen bone autograft for malignant acetabular bone tumors: a report of two cases
}

Kensaku Abe, Norio Yamamoto, Katsuhiro Hayashi* ㅁ, Akihiko Takeuchi, Shinji Miwa, Kentaro Igarashi, Hiroyuki Inatani, Yu Aoki, Takashi Higuchi, Yuta Taniguchi, Hirotaka Yonezawa, Yoshihiro Araki and Hiroyuki Tsuchiya

\begin{abstract}
Background: Difficult resection of tumors from regions with complex local anatomy, such as the pelvis and sacrum, is likely to result in inadequate surgical margins (intralesional or marginal); this is because three-dimensional osteotomy is difficult particularly around the acetabulum. Additionally, removal of the joint makes reconstruction very difficult; thus, retention of good function also becomes difficult. In musculoskeletal oncology, computer navigation systems are still not widely used to prevent tumor-positive margins. We performed wide excision with guidance from a computer navigation system and reconstruction using frozen bone autografts for malignant pelvic bone tumors in two patients, and we obtained excellent functional and oncological outcomes. Here we present these patients and discuss our approach.

Case presentation: Case 1: A 12-year-old girl presented with Ewing sarcoma of the left pelvis (PI-II). We performed wide excision assisted by a computer navigation system with the osteotomy of the load surface of acetabulum and reconstruction using a frozen bone autograft. At the final follow-up, she showed excellent function and was alive without the disease. Moreover, she did not have osteoarthritis of the left hip joint.

Case 2: A 71-year-old woman presented with dedifferentiated chondrosarcoma of the right pelvis (PII-III). We performed wide excision assisted by a computer navigation system with osteotomy avoiding load surface of the acetabulum and reconstruction using a frozen bone autograft; there was no tumor at the load surface. At the final follow-up, she showed good function, was alive without the disease, and did not have osteoarthritis of the left hip joint.

Conclusions: Wide excision assisted by a computer navigation system and reconstruction using a frozen bone autograft are very useful for the management/treatment of extremely difficult cases such as malignant pelvic bone tumors, particularly those including the acetabulum.
\end{abstract}

Keywords: Ewing sarcoma, Dedifferentiated chondrosarcoma, Acetabulum, Computer navigation system, Frozen autograft, Reconstruction

\footnotetext{
* Correspondence: khayashi830@gmail.com

Department of Orthopaedic Surgery, Graduate School of Medical Sciences,

Kanazawa University, 13-1 Takara-machi, Kanazawa 920-8641, Japan
}

(c) The Author(s). 2018 Open Access This article is distributed under the terms of the Creative Commons Attribution 4.0 International License (http://creativecommons.org/licenses/by/4.0/), which permits unrestricted use, distribution, and reproduction in any medium, provided you give appropriate credit to the original author(s) and the source, provide a link to the Creative Commons license, and indicate if changes were made. The Creative Commons Public Domain Dedication waiver (http://creativecommons.org/publicdomain/zero/1.0/) applies to the data made available in this article, unless otherwise stated. 


\section{Background}

Difficult resection of tumors from regions with complex local anatomy, such as the pelvis and sacrum, or from regions that require complex multiplanar or geometric bony resection, is likely to result in inadequate surgical margins (intralesional or marginal) [1]. This can drastically affect a patient's outcome, and it may result in local tumor recurrence in up to $92 \%$ of cases [2-8]. The use of computer navigation systems in spinal surgery, arthroplasty, deformity correction, and trauma has improved surgical precision by providing more detailed intraoperative information and guidance [9-14]. However, computer navigation systems are yet to be widely used in musculoskeletal oncology, although many authors have also reported encouraging results, such as a good intraoperative orientation, precise surgical margins, low rates of local recurrence and complications, and good functional outcomes because of the possibility of pelvic reconstruction [15-19].

Pelvic resection called PII according to Enneking and Dunham [20] and periacetabular resection present a unique surgical challenge as no specific reconstruction approach has been shown to be superior [21]. Although many reconstructive options exist, the best reconstructive option for these patients is still being debated. The options include endoprosthetic reconstruction [22-24], hip transposition [25, 26], iliofemoral arthrodesis [27, 28 ], biological reconstruction (using allografts or autografts from the tibia, fibula, iliac crest, or pelvis) [29, 30], and hip rotationplasty [31]. In our institution, we have developed a novel surgical procedure involving reconstruction using frozen autografts [32, 33] (Fig. 1). This method has been shown to be associated with particularly excellent functional and oncological outcomes [32-38].

We performed wide excision with guidance from a computer navigation system and reconstruction using frozen bone autografts for malignant pelvic bone tumors in two patients, and we obtained excellent functional and oncological outcomes. Here, we present these patients and discuss our approach.

\section{Operative methods using computer navigation}

We used OrthoMap software (Stryker, Kalamazoo, Michigan) as a computer navigation system. In the preoperative plan, the plot was based on computed tomography (CT) (case 1) or both CT and gadolinium-enhanced magnetic resonance imaging (MRI) (case 2). The CT and MRI slice thicknesses were 1.5 and $4 \mathrm{~mm}$, respectively. We used only CT for case 1 because chemotherapy was extremely effective and the soft tissue mass disappeared; we used both CT and MRI for case 2 because chemotherapy was less effective and the soft tissue mass remained. We confirmed that the tumor did not grow in size 1 week before surgery, and then, we used the image acquired before chemotherapy. If the tumor grows, then, it is considered that the image should be the latest one. This process took 2-3 h. During the operation, the navigation station was located on the opposite side of the operator to eliminate any obstacles between the camera and the patient's/instrument's tracker. The patient's tracker was placed on the iliac crest, and registration points were registered until the error was $<1 \mathrm{~mm}$ using the anterior superior iliac spine, sacroiliac joint, and exposed iliac crest as the registration points with comparisons with $3 \mathrm{D}$ imaging. Once we determined the osteotomy site, bones were cut using a chisel linked with navigation, a bone saw, and a threadwire saw (T-saw; Depuy AcroMed, Inc., Cleveland, $\mathrm{OH}$ ) [39-42]. Although determining navigation settings requires $30-60 \mathrm{~min}$, doubts about determining osteotomy sites were dramatically reduced. The resection margin was pathologically confirmed using a small sample collected from a preserved host tissue.

\section{Operative methods using frozen autografts}

The surgical procedure has previously been described [32]. To kill the tumor cells, rapid freezing and slow thawing were performed. In particular, the tumorbearing bone was frozen in liquid nitrogen for $20 \mathrm{~min}$, thawed at room temperature, and distilled in water for $15 \mathrm{~min}$. When the tumor-bearing bone was frozen, moisture was removed, the bone marrow cavity was

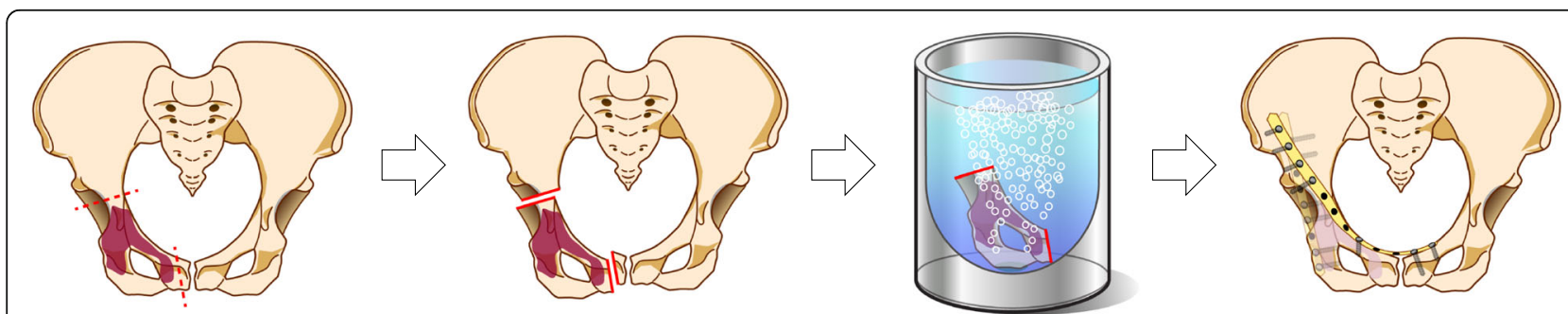

Fig. 1 Pelvic osteotomy and free-freezing method. The tumor is first excised by osteotomy. Then, after peeling off the soft tissue, we performed curettage of the tumor and drilling to prevent bone breakage. After freezing in liquid nitrogen, osteosynthesis was performed using plates, screws, and a bone graft 
curettaged, and the bone was punctured in multiple places using a Kirschner wire to prevent fracture. The frozen autograft was replaced with the reconstruction. Bone graft or cement was used for mechanical support when necessary.

\section{Case presentations \\ Case 1}

A 12-year-old girl presented with Ewing sarcoma of the left pelvis (PI-II). Neoadjuvant chemotherapy (4 courses of ifosfamide + etoposide and 4 courses of vincristine + doxorubicine + cyclophosphamide) was administered, and the extra-skeletal mass disappeared on MRI. Wide excision and reconstruction were performed. We planned osteotomy including the load surface of acetabulum assisted by a computer navigation system and reconstruction using a frozen bone autograft. The patient's tracker was placed on the iliac crest; the error after registration was within $1 \mathrm{~mm}$. Subsequently, by pulling the lower limbs, a gap of approximately $2 \mathrm{~cm}$ was made in the joint space and osteotomy was performed without dislocation of the hip joint (Fig. 2). In this case, navigation was particularly helpful in osteotomy of the acetabulum. Although osteotomy under direct view is possible via dislocation of the hip joint, it involves the risk of femoral head necrosis, and this cannot be confirmed from the cartilage surface. In addition, $\mathrm{X}$-ray image alone cannot provide the orientation. Reconstruction was performed using plates and an artificial bone graft and autograft (normal iliac bone) to fill the cavity for the defect of the load surface of acetabulum after tumor curettage. The resection margins were free of tumor, and this was pathologically confirmed in a small sample collected from preserved host tissue. Pathological evaluation of curettage of cancellous bone indicated almost total necrosis of the tumor, which was classified as grade III/IV according to the Rosen and Huvos evaluation system [43]. After the completion of postoperative chemotherapy (three courses of ifosfamide + etoposide, 1 course of vincristine + doxorubicine + cyclophosphamide, and two courses of vincristine + cyclophosphamide), the patient was free of the disease. Her X-ray did not show osteoarthritis of the hip joint; she could walk normally with some claudication, and there were no limitations in the sitting posture (no limitation of the range of motion of the hip and knee joint) at her 23-month follow-up (Fig. 3). Moreover, we evaluated the outcome at the 23-month follow-up using the Musculoskeletal Tumor Society (MSTS) score [44], Toronto Extremity Salvage Score (TESS) [45], and 36-item Short-form Health Survey (SF-36) [46, 47]. Her MSTS score was 86.7 and TESS was 86.5. Additionally, her physical component summary, mental component summary, and role-social component summary scores in the
SF-36 were 39.4, 59.9, and 44.1, respectively (each summary had a mean of 50 and a standard deviation of 10 , according to data from 2007 for healthy Japanese individuals [47]).

\section{Case 2}

A 71-year-old woman presented with dedifferentiated chondrosarcoma of the right pelvis (PII-III). The initial pathological diagnosis was osteosarcoma, and thus, neoadjuvant chemotherapy ( 3 courses of cisplatin + doxorubicine) was administered. The chemotherapy caused marked shrinkage and ossification of the tumor. Wide excision and reconstruction were performed. We planned osteotomy avoiding load surface of the acetabulum, in which there was no tumor, assisted by a computer navigation system. The patient's tracker was placed on the iliac crest, and the error after registration was within $1 \mathrm{~mm}$. In this case, navigation was also particularly useful for osteotomy of the acetabulum. The location and orientation of osteotomy were extremely important for preserving the load surface, but similar to other methods, it is currently impossible to precisely achieve this. Reconstruction was performed using plates and a frozen bone autograft (Fig. 4). The resection margins were free of tumor, and this was pathologically confirmed in a small sample collected from preserved host tissue. Pathological evaluation of curettage of the tumor, which was classified as grade II/IV according to the Rosen and Huvos evaluation system. The patient did not undergo postoperative chemotherapy as the final diagnosis was dedifferentiated chondrosarcoma (resistant to chemotherapy), and her physical status was limited. However, she was free of the disease her X-ray did not show osteoarthritis of the hip joint. She could walk almost normally with a cane at her 33-month follow-up. At that follow-up, her MSTS score was 63.3 and TESS was 68.8. Additionally, her physical component summary, mental component summary, and role-social component summary scores in the SF-36 were 26.0, 58.8, and 33.1, respectively.

\section{Discussion}

Consistent with the findings of previous studies [15-19], both our cases successfully underwent excision with tumor-free margins associated with the use of a computer navigation system. Previous reports by Jeys $\mathrm{L}$ et al. [19], Cho HS et al. [48], and Wong KC et al. [49] included 31, 10, and 12 patients, respectively, and these patients underwent resection under computer navigation for a pelvic or sacral bone tumor. These reports mentioned that computer navigation was a safe technique with no specific complications. In these reports, the rates of tumor-free margins were $90.3 \%$ (28/31), 100\% $(10 / 10)$, and $100 \%(12 / 12)$, respectively. However, the 
a

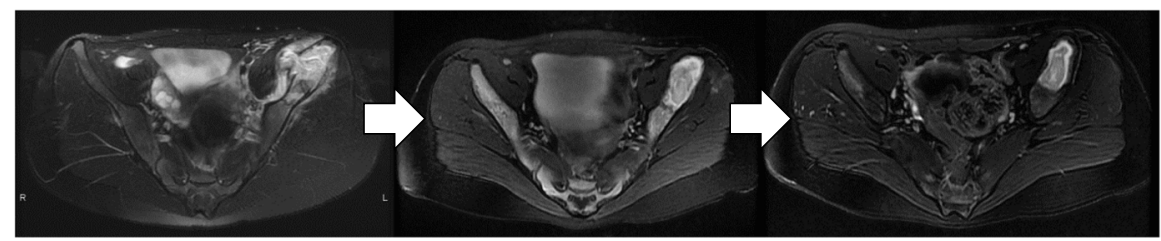

b

C

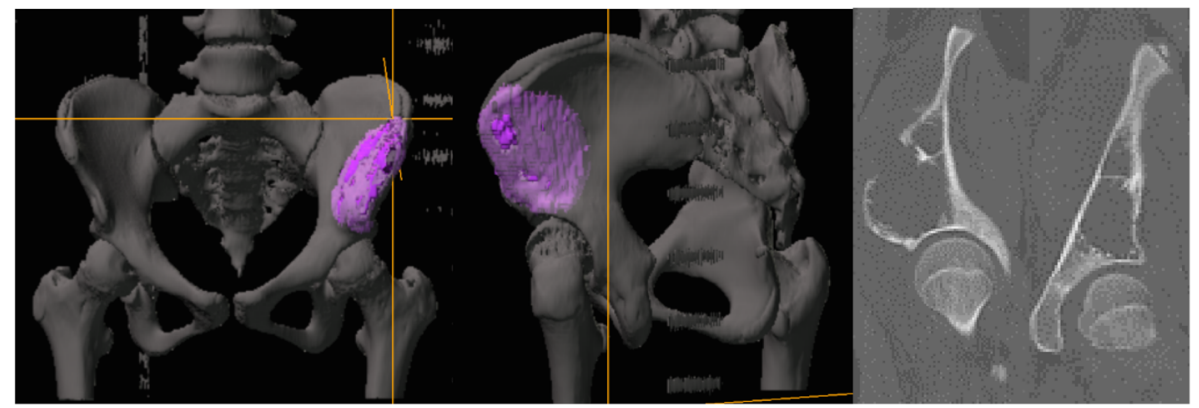

d

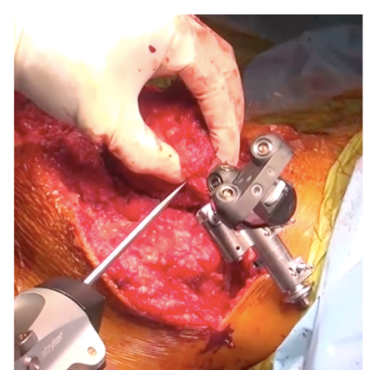

e

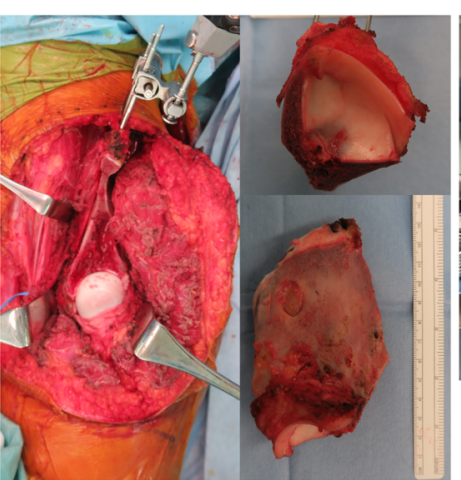

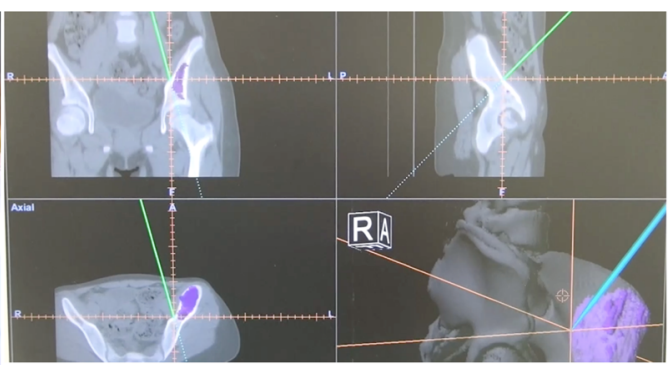

f

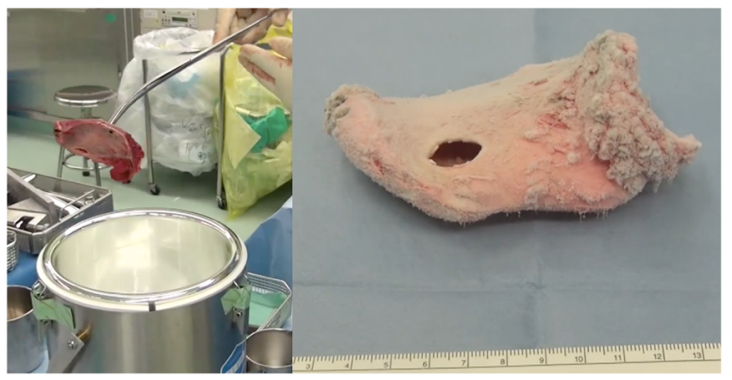

Fig. 2 Preoperative assessments in case 1: A 12-year-old girl with Ewing sarcoma of the pelvis (PI-II). a Preoperative magnetic resonance imaging. b) Preoperative plan involving the use of a computer navigation system. c) Preoperative computed tomography. $\mathbf{d}$ Checking the margin using a computer navigation system. e After osteotomy. f Freezing in liquid nitrogen

local recurrence rates were $9.7 \%(3 / 31), 20 \%(2 / 10)$, and $25 \%(3 / 12)$, respectively. In the first report, the bone resection margin was clear, but the soft-tissue resection margin was intralesional in all cases. Although computer navigation allows more accurate resection in patients with pelvic and sacral tumors, a clear resection margin alone does not appear to prevent local recurrence. The use of navigation can only improve the accuracy of bony resection and avoid inadvertent perforation of the tumor with osteotomy. The narrow soft-tissue margins associated with the pelvis cannot be improved by using navigation [19]. Our patients had tumor-free margins for not only bone but also soft tissue, and they are presently free of the disease. However, these results were not completely accurate as one of the disadvantages of reconstruction using a frozen autograft is the inability to 


\section{a}

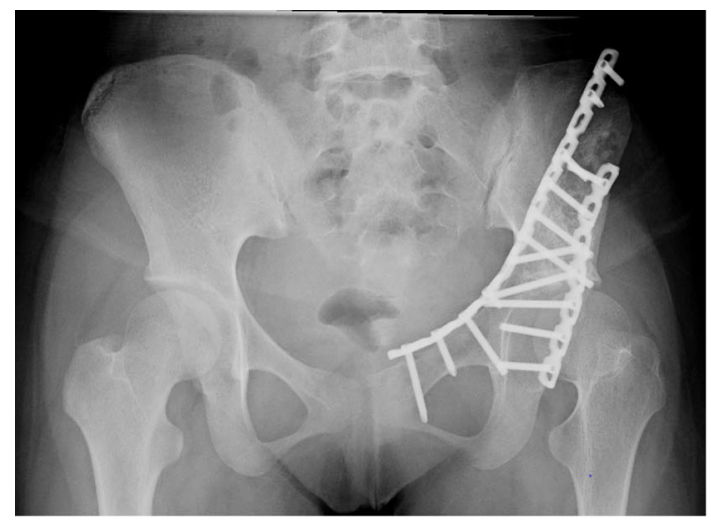

\section{C}

b
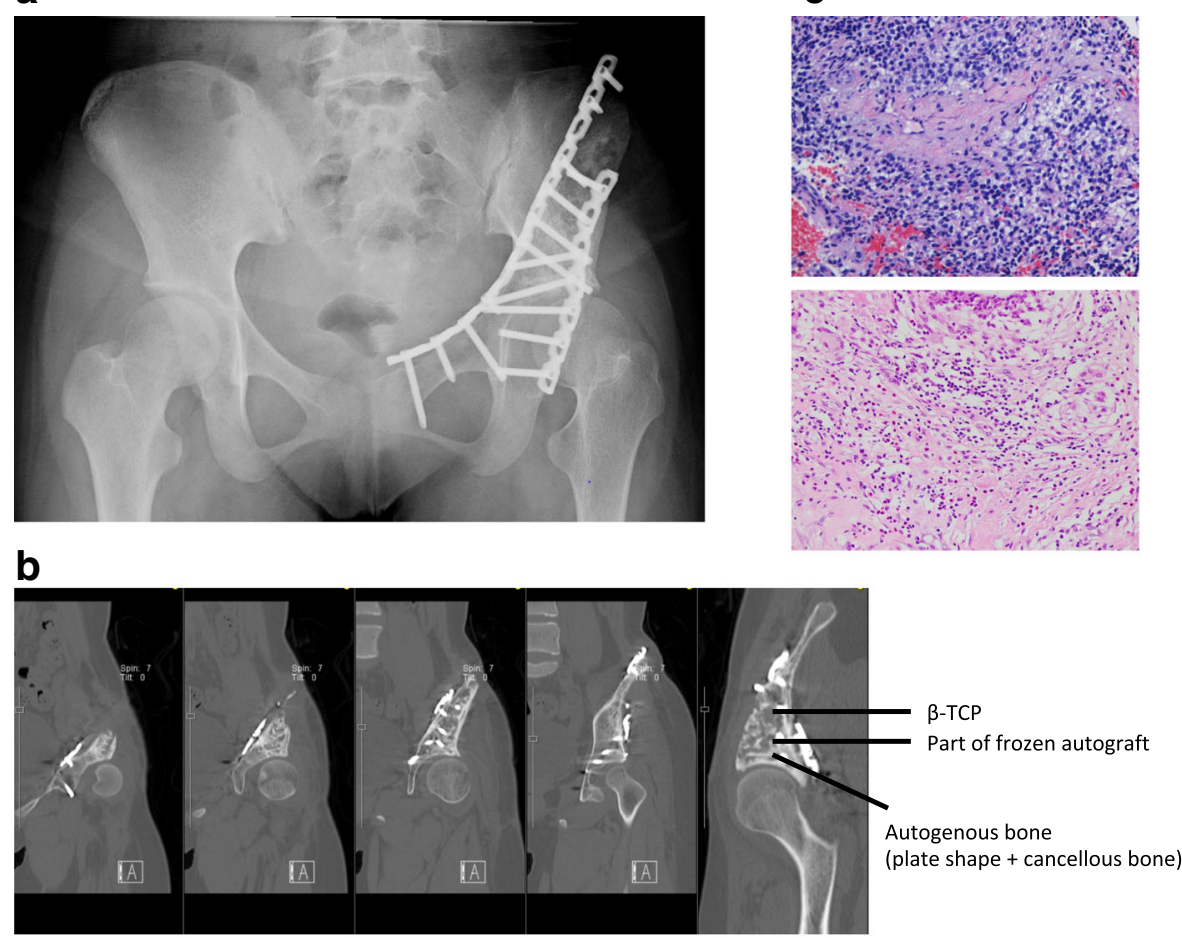

d

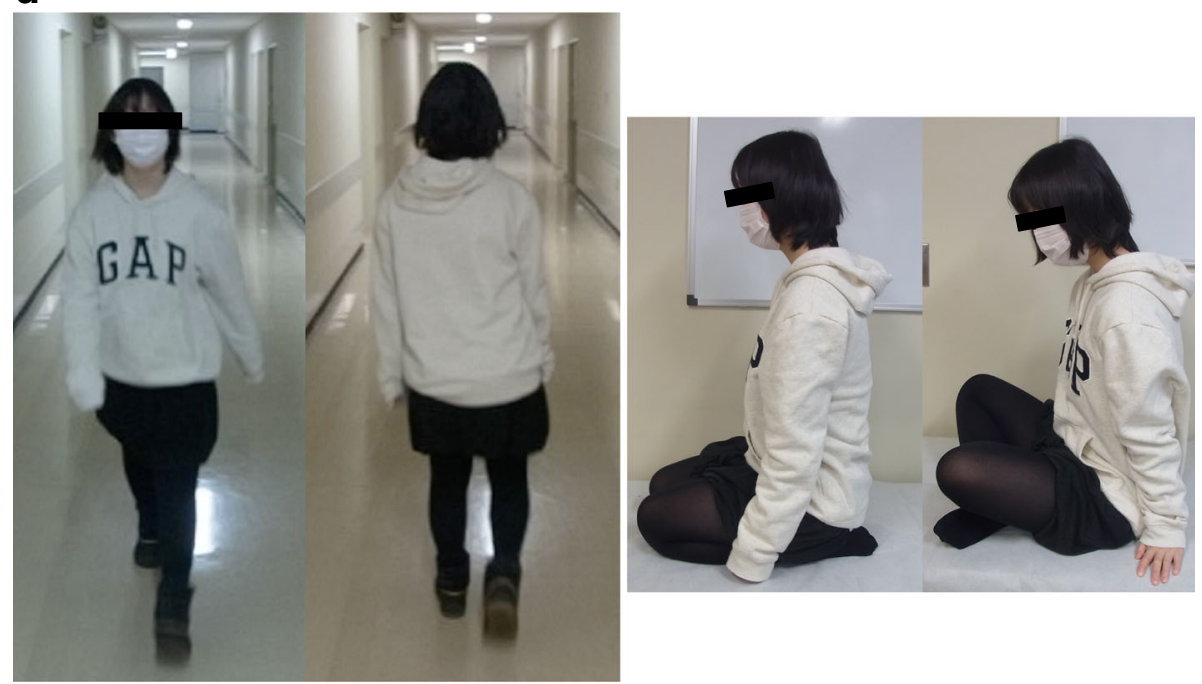

Fig. 3 Postoperative assessments in case 1: A 12-year-old girl with Ewing sarcoma of the pelvis (PI-II). a Radiograph obtained at 23 months after reconstruction. b Computed tomography at 23 months after reconstruction. Bone union is observed, and osteoarthritis is not yet observed. c Pathological findings at biopsy (upper panel) and post-neoadjuvant chemotherapy (lower panel). After neoadjuvant chemotherapy, a necrotic change was observed. $\mathbf{d}$ She can walk almost normally, and there are no limitations in the sitting posture

perform histological analysis of the whole specimen. This is one of the limitations of our approach. In contrast to traditional intraoperative $2 \mathrm{D} \mathrm{X}$-ray image guidance, the technique completely utilizes $\mathrm{CT}$ and $\mathrm{MR}$ images and 3D models for real-time osteotomy guidance. This may improve surgical accuracy by decreasing intralesional resection and maximally preserving normal bone tissue. In these cases, partial acetabular preservation was performed. A perfect fit cannot be achieved, except by recycling the autograft, and this is the only method for reconstruction after the osteotomy adhered, as observed in this case.

Periacetabular reconstruction is challenging and no single reconstructive strategy has been proven to be 


\section{a}
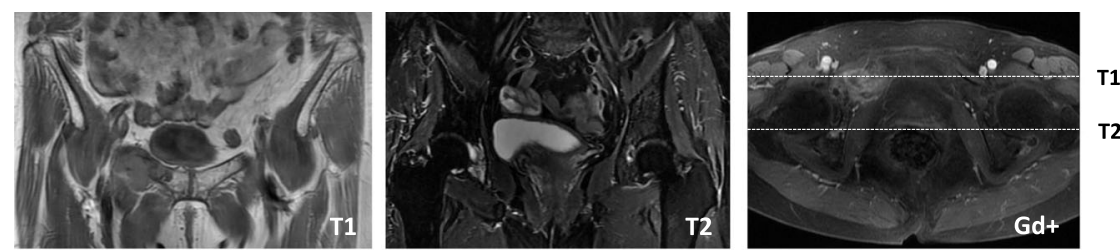

b

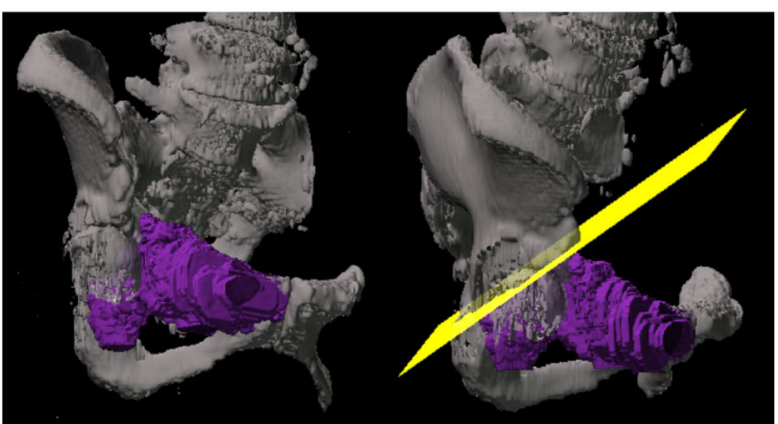

g

C

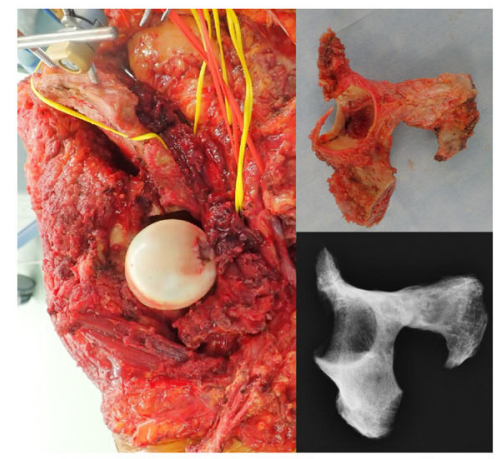

e

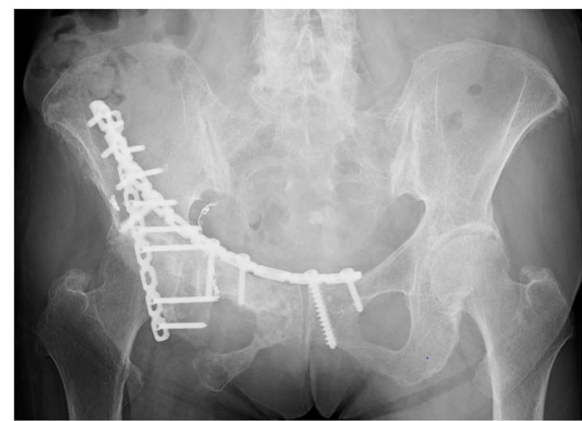

d

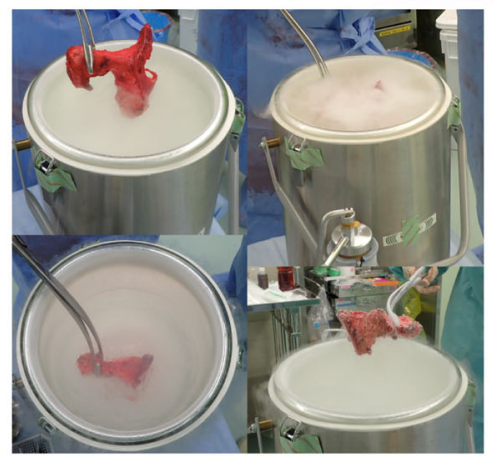

f

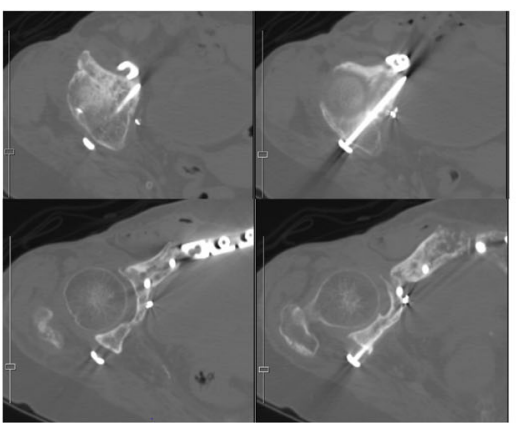

Fig. 4 Preoperative and postoperative assessments in case 2: A 71-year-old woman with dedifferentiated chondrosarcoma of the pelvis (PII-III). a) Preoperative magnetic resonance imaging. $\mathbf{b}$ Preoperative plan involving the use of a computer navigation system. The osteotomy line was planned as indicated by the yellow surface. $\mathbf{c}$ After osteotomy $\mathbf{d}$ Procedure of freezing in liquid nitrogen. e Radiograph obtained at 33 months after reconstruction. $\mathbf{f}$ Computed tomography at 33 months after reconstruction. Bone union is observed, and osteoarthritis is not very prominent. g Pathological findings at biopsy (upper panel) and post-neoadjuvant chemotherapy (lower panel). After neoadjuvant chemotherapy, a necrotic change was observed

superior [50]. Saddle prosthesis was initially popular because of its ease of insertion and its proposed benefits of preservation of length and hip mobility as compared with fusion; however, with reports of poor function and high complication rates, the technique has fallen out of favor [51]. Later generations of endoprosthesis that relied upon fixation to the remnant ilium have also suffered from high rates of instability, loosening, and 
Table 1 Postoperative assessment scores (MSTS score, TESS, and SF-36) on literature review

\begin{tabular}{|c|c|c|c|c|c|c|c|}
\hline \multirow[t]{2}{*}{ Study } & \multirow[t]{2}{*}{ Surgical procedures } & \multirow{2}{*}{$\begin{array}{l}\text { Number } \\
\text { of patients }\end{array}$} & \multirow{2}{*}{$\begin{array}{l}\text { MSTS } \\
\text { score (\%) }\end{array}$} & \multirow{2}{*}{$\begin{array}{l}\text { TESS } \\
(\%)\end{array}$} & \multicolumn{3}{|c|}{ SF-36 } \\
\hline & & & & & PCS & MCS & RCS \\
\hline \multirow[t]{4}{*}{ Fujiwara T, et al. [56] } & Endoprosthesis & 11 & 42 & N/A & N/A & N/A & N/A \\
\hline & Hip transposition & 4 & 49 & N/A & N/A & N/A & N/A \\
\hline & Iliofemoral arthrodesis & 2 & 68 & N/A & N/A & N/A & N/A \\
\hline & Frozen autograft & 1 & 50 & N/A & N/A & N/A & N/A \\
\hline \multirow[t]{2}{*}{ Fuchs B, et al. [28] } & \|liofemoral arthrodesis & 21 & 71 & 76 & N/A & N/A & N/A \\
\hline & Hip transposition & 11 & 25 & 52 & N/A & N/A & N/A \\
\hline Kim HS, et al. [57] & Pasteurized autograft & 11 & 61 & N/A & N/A & N/A & N/A \\
\hline Cottias P, et al. [58] & Saddle prosthesis & 17 & 57 & 58 & N/A & N/A & N/A \\
\hline Abdu A, et al. [22] & Custom-made hemipelvic endoprosthesis & 35 & 70 & N/A & N/A & N/A & N/A \\
\hline Jaiswal PK, et al. [23] & Custom-made hemipelvic endoprosthesis & 98 & N/A & 60 & N/A & N/A & N/A \\
\hline Our case: 12-year-old girl & Frozen autograft & 1 & 87 & 87 & 39 & 60 & 44 \\
\hline Our case: 71-year-old woman & Frozen autograft & 1 & 63 & 69 & 26 & 59 & 33 \\
\hline
\end{tabular}

MSTS Musculoskeletal Tumor Society; TESS Toronto Extremity Salvage Score; SF-36 36-item Short-form Health Survey; PCS Physical component summary; MCS Mental component summary; RCS Role-social component summary; N/A Not available

infection [52-55]. Anatomical reconstruction of a functional hip joint seems desirable [50]. In our cases, using a frozen autograft, we were able to realize the anatomical reconstruction, and good results were obtained. Conversely, several complications were reported, such as infection, fracture, non-union, limb length discrepancy, and bone absorption [34-37]. However, no complications were noted at the 23- and 33-month short-term follow-up visits. Although freezing, in our cases, extended to the joints, not all surfaces of the joints were frozen. If the joint capsule and ligaments are solid, then stability is good, and the possibility of long-term maintenance exists.

The postoperative assessment scores (MSTS score, TESS, and SF-36) in our cases and in cases from other reports are summarized in Table 1 . When our cases were compared with previous cases, our younger case (case 1) showed superior outcomes, while our older case (case 2) showed outcomes that were neither superior nor inferior. Moreover, the mental component summary score in the SF-36 was high in both our cases, suggesting that the patients were satisfied with the operation. Problems such as the degree of improvement in function with age and the transition to osteoarthritis in the future can vary, but in order to obtain better function and satisfaction, reconstruction using a frozen bone autograft is suggested to be very useful.

In conclusion, our patients with malignant acetabular bone tumors were successfully treated with our approach. They were free of the disease and had excellent function. Wide excision with guidance from a computer navigation system and reconstruction using a frozen bone autograft appear to be very useful for the treatment of a malignant acetabular bone tumor.

\section{Abbreviations}

CT: computed tomography; MRI: magnetic resonance imaging; MSTS: Musculoskeletal Tumor Society; SF-36: 36-item Short-form Health

Survey; TESS: Toronto Extremity Salvage Score

\section{Acknowledgments}

Not applicable.

\section{Funding}

Not applicable.

\section{Availability of data and materials}

To protect privacy and respect confidentiality, no raw data have been made available in any public repository. The original operation reports, intraoperative photographs, imaging studies, and outpatient clinic records are retained as per the normal procedure within medical records of our institution. The datasets used and/or analysed during the current study available from the corresponding author on reasonable request.

\section{Authors' contributions}

All listed authors substantially contributed to the following aspects of the manuscript: KA, KH, NY, AT, SM, KI, HI, and HT participated in diagnosing and treating the patient and in acquisition of data. $\mathrm{KA}, \mathrm{YA}, \mathrm{TH}, \mathrm{YT}, \mathrm{HY}$, and $\mathrm{YA}$ collected the findings and drafted the manuscript. NY, KH, and $\mathrm{HT}$ revised the manuscript. All authors read and approved the final manuscript. Dr. Katsuhiro Hayashi and Dr. Hiroyuki Tsuchiya guarantee the integrity of this work.

\section{Ethics approval and consent to participate}

Not applicable. However, based on the rules of our institute, this study was approved by the Institutional Review Board of the Kanazawa University Graduate School of Medical Science Kanazawa, Japan. All procedures were performed as part of standard medical care. Written consent to publish was obtained from the patients themselves and from their parents (Case 1) or husband (Case 2).

\section{Consent for publication}

Written informed consent was obtained from the patient for the publication of this case report and any accompanying images. A copy of the written consent form is available for review by the Editor of this journal.

\section{Competing interests}

The authors declare that they have no competing interests. 


\section{Publisher's Note}

Springer Nature remains neutral with regard to jurisdictional claims in published maps and institutional affiliations.

Received: 11 September 2018 Accepted: 18 October 2018 Published online: 24 October 2018

\section{References}

1. Young PS, Bell SW, Mahendra A. The evolving role of computer-assisted navigation in musculoskeletal oncology. Bone Joint J. 2015;97-B(2):258-64.

2. Wirbel RJ, Schulte M, Mutschler WE. Surgical treatment of pelvic sarcomas: oncologic and functional outcome. Clin Orthop Relat Res. 2001;390:190-205.

3. Pring ME, Weber KL, Unni KK, Sim FH. Chondrosarcoma of the pelvis; a review of sixty-four cases. J Bone Joint Surg Am. 2001;83-A(11):1630-42.

4. Kawai A, Huvos AG, Meyers PA, Healey JH. Osteosarcoma of the pelvis; oncologic results of 40 patients. Clin Orthop Relat Res. 1998;348:196-207.

5. Sucato DJ, Rougraff B, McGrath BE, et al. Ewing's sarcoma of the pelvis; longterm survival and functional outcome. Clin Orthop Relat Re. 2000;373: 193-201.

6. Fuchs B, Hoekzema N, Larson DR, Inwards CY, Sim FH. Osteosarcoma of the pelvis: outcome analysis of surgical treatment. Clin Orthop Relat Res. 2009; 467:510-8.

7. Court C, Bosca L, Le Cesne A, Nordin JY, Missenard G. Surgical excision of bone sarcomas involving the sacroiliac joint. Clin Orthop Relat Res. 2006; 451:189-94.

8. Cho HS, Kang HG, Kim HS, Han I. Computer-assisted sacral tumor resection; a case report. J Bone Joint Surg Am. 2008;90-A(7):1561-6.

9. Gebhard F, Weidner A, Liener UC, Stöckle U, Arand M. Navigation at the spine. Injury. 2004;35(Suppl 1):S-A35-45.

10. Anderson KC, Buehler KC, Markel DC. Computer assisted navigation in tota knee arthroplasty: comparison with conventional methods. J Arthroplast. 2005;20(7 Suppl 3):132-8.

11. Wixson RL, MacDonald MA. Total hip arthroplasty through a minimal posterior approach using imageless computer-assisted hip navigation. J Arthroplast. 2005;20(7 Suppl 3):51-6.

12. Stiehl JB, Heck DA. Computer-assisted surgery: basic concepts. Instr Course Lect. 2008:57:689-97.

13. Hüfner T, Pohlemann T, Tarte S, Gänsslen A, Geerling J, Bazak N, Citak M, Nolte LP, Krettek C. Computer-assisted fracture reduction of pelvic ring fractures: an in vitro study. Clin Orthop Relat Res. 2002;399:231-9.

14. Grützner PA, Suhm N. Computer aided long bone fracture treatment. Injury. 2004;35(Supp 11):S-A57-64.

15. Krettek C, Geerling J, Bastian L, Citak M, Rücker F, Kendoff D, Hüfner T. Computer aided tumor resection in the pelvis. Injury. 2004;35(Supp I1):SA79-83.

16. Cheong D, Letson GD. Computer-assisted navigation and musculoskeletal sarcoma surgery. Cancer Control. 2011;18(3):171-6.

17. So TY, Lam YL, Mak KL. Computer-assisted navigation in bone tumor surgery: seamless workflow model and evolution of technique. Clin Orthop Relat Res. 2010:468:2985-91.

18. Wu K, Webber NP, Ward RA, Jones KB, Randall RL. Intraoperative navigation for minimally invasive resection of periarticular and pelvic tumors. Orthopedics. 2011;34(5):372.

19. Jeys L, Matharu GS, Nandra RS, Grimer RJ. Can computer navigation-assisted surgery reduce the risk of an intralesional margin and reduce the rate of local recurrence in patients with a tumour of the pelvis or sacrum? Bone Joint J. 2013; 95-(10)B: 1417-1424.

20. Enneking WF, Dunham WK. Resection and reconstruction for primary neoplasms involving the innominate bone. J Bone Joint Surg Am. 1978;60: 731-46.

21. Hugate R Jr, Sim FH. Pelvic reconstruction techniques. Orthop Clin North Am. 2006;37(1):85-97.

22. Abudu A, Grimer RJ, Cannon SR, Carter SR, Sneath RS. Reconstruction of the hemipelvis after the excision of malignant tumours. J Bone Joint Surg $\mathrm{Br}$. 1997;79(5):773-9.

23. Jaiswal PK, Aston WJ, Grimer RJ, Abudu A, Carter S, Blunn G, Briggs TW, Cannon S. Peri-acetabular resection and endoprosthetic reconstruction for tumours of the acetabulum. J Bone Joint Surg Br. 2008;90(9):1222-7.

24. Ueda T, Kakunaga S, Takenaka S, Araki N, Yoshikawa H. Constrained total hip megaprosthesis for primary periacetabular tumors. Clin Orthop Relat Res. 2013;471(3):741-9.
25. Gebert C, Gosheger G, Winkelmann W. Hip transposition as a universal surgical procedure for periacetabular tumors of the pelvis. J Surg Oncol. 2009;99(3):169-72

26. Gebert C, Wessling M, Hoffmann C, Roedl R, Winkelmann W, Gosheger G, Hardes J. Hip transposition as a limb salvage procedure following the resection of periacetabular tumors. J Surg Oncol. 2011; 103(3):269-75.

27. Carmody Soni EE, Miller BJ, Scarborough MT, Parker Gibbs C. Functional outcomes and gait analysis of patients after periacetabular sarcoma resection with and without ischiofemoral arthrodesis. J Surg Oncol. 2012;106(7):844-9.

28. Fuchs B, O'Connor MI, Kaufman KR, Padgett DJ, Sim FH. Iliofemoral arthrodesis and pseudarthrosis: a longtermfunctional outcome evaluation. Clin Orthop Relat Res. 2002;397:29-35.

29. Campanacci D, Chacon S, Mondanelli N, Beltrami G, Scoccianti G, Caff G, Frenos F, Capanna R. Pelvicmassive allograft reconstruction after bone tumour resection. Int Orthop. 2012;36(12):2529-36.

30. Laffosse JM, Pourcel A, Reina N, Tricoire JL, Bonnevialle P, Chiron P, Puget J. Primary tumor of the periacetabular region: resection and reconstruction using a segmental ipsilateral femur autograft. Orthop Traumatol Surg Res. 2012:98(3):309-18.

31. Winkelmann WW. Hip rotationplasty for malignant tumors of the proximal part of the femur. J Bone Joint Surg Am. 1986;68(3):362-9.

32. Tsuchiya H, Wan SL, Sakayama K, Yamamoto N, Nishida H, Tomita K. Reconstruction using an autograft containing tumour treated by liquid nitrogen. J Bone Joint Surg Br. 2005;87:218-25.

33. Tsuchiya H, Nisida H, Srisawat P, Shirai T, Hayashi K, Takeuchi A, Yamamoto $\mathrm{N}$, Tomita K. Pedicle frozen autograft reconstruction in malignant bone tumors. J Orhtop Sci. 2010;15:340-9.

34. Higuchi T, Yamamoto N, Nishida H, Hayashi K, Takeuchi A, Kimura H, Miwa S, Inatani H, Shimozaki S, Kato T, Aoki Y, Abe K, Taniguchi Y, Tsuchiya H. Knee joint preservation surgery in osteosarcoma using tumour-bearing bone treated with liquid nitrogen. Int Orthop. 2017.

35. Zerly KM, Yamamoto N, Hayashi K, Takeuchi A, Higuchi T, Abe K, Taniguchi Y, Alkhooly AZAA, Abd-Elfattah AS, Fouly EH, Ahmed AR, Tsuchiya $\mathrm{H}$. Intercalary frozen autograft for reconstruction of malignant bone and soft tissue tumours. Int Orthop. 2017:41:1481-7.

36. Igarashi K, Yamamoto N, Shirai T, Hayashi K, Nishida H, Kimura H, Takeuchi A, Tsuchiya $\mathrm{H}$. The long-term outcome following the use of frozen autograft treated with liquid nitrogen in the management of bone and soft-tissue sarcomas. Bone Joint J. 2014;96-B:555-61.

37. Shimozaki S, Yamamoto N, Shirai T, Nishida H, Hayashi K, Tanzawa Y, Kimura $\mathrm{H}$, Takeuchi A, Igarashi $\mathrm{K}$, Inatani $\mathrm{H}$, Kato T, Tsuchiya $\mathrm{H}$. Pedicle cersus free frozen autograft for reconstruction in malignant bone and soft tissue tumors of the lower extremities. J Orthop Sci. 2014;19:156-63.

38. Miwa S, Takeuchi A, Ikeda H, Shirai T, Yamamoto N, Nishida H, Hayashi K, Tanzawa Y, Kimura H, Igarashi K, Tsuchiya H. Prognostic value of histological response to chemotherapy in osteosarcoma patients receiving tumorbearing frozen autograft. PLoS One. 2013;8:e71362.

39. Tomita K, Kawahara N. The threadwire saw: a new device for cutting bone. J Bone Joint Surg Am. 1996:78:1915-7.

40. Tomita K, Kawahara N, Baba H, Tsuchiya H, Nagata S, Toribatake Y. Total en bloc spondylectomy for solitary spinal metastasis. Int Orthop. 1994;18:291-8.

41. Tomita K, Kawahara N, Baba H, Tsuchiya H, Fujita T, Toribatake Y. Total en bloc spondylectomy: a new surgical technique for primary malignant vertebral tumors. Spine. 1997;22:324-33.

42. Tomita K, Kawahara N, Toribatake Y, Heller JG. Expansive midline T-saw laminoplasty (modified spinous process splitting) for the management of cervical myelopathy. Spine. 1998;23:32-7.

43. Rosen G, Marcove RC, Caparros B, Nirenberg A, Kosloff C, Huvos AG. Primary osteogenic sarcoma: the rationale for preoperative chemotherapy and delayed surgery. Cancer. 1979:43:2163-77.

44. Enneking WF, Dunham W, Gebhardt MC, Malawar M, Pitchard DJ. A system for the functional evaluation of reconstructive procedures after surgical treatment of tumors of the musculoskeletal system. Clin Orthop Relat Res. 1993:(286):241-6.

45. Davis AM, Wright JG, Williams Jl, Bombardier C, Griffin A, Bell RS. Development of a measure of physical function for patients with bone and soft tissue sarcoma. Qual Life Res. 1996;5:508-16.

46. Ware JE Jr, Sherbourne CD. The MOS 36-item short-form health survey (SF36): I. conceptual framework and item selection. Med Care. 1992;30:473-83. 
47. Fukuhara S, Bito S, Green J, Hsiao A, Kurokawa K. Translation, adaptation, and validation of the SF-36 health survey for use in Japan. J Clin Epidemiol. 1998;51:1037-44.

48. Cho HS, Oh JH, Han I, Kim HS. The outcomes of navigation-assisted bone tumour surgery: minimum three-year follow-up. J Bone Joint Surg [Br]. 2012; 94-B:1414-20

49. Wong KC, Kumta SM. Computer-assisted tumor surgery in malignant bone tumors. Clin Orthop Relat Res. 2013;471:750-61.

50. Chan LW, Imanishi J, Ngan SY, Chander S, Chu J, Thorson R, Pang G, Choong P. Extracorporeal irradiation and Reimplantation with Total hip arthroplasty for Periacetabular pelvic resections: a review of 9 cases. Sarcoma. 2016;2016:2549616.

51. Jansen JA, van de Sande MA, Dijkstra PD. Poor long-term clinical results of saddle prosthesis after resection of periacetabular tumors. Clin Orthop Relat Res. 2013:471:324-31.

52. Bus MP, Boerhout EJ, Bramer JA, Dijkstra PD. Clinical outcome of pedestal cup endoprosthetic reconstruction after resection of a peri-acetabular tumour. Bone Joint J. 2014;96B:1706-12.

53. Fisher NE, Patton JT, Grimer RJ, Porter D, Jeys L, Tillman RM, Abudu A, Carter SR. Ice-cream cone reconstruction of the pelvis: a new type of pelvic replacement: early results. J Bone Joint Surg Br. 2011;93:684-8.

54. Witte D, Bernd L, Bruns J, Gosheger G, Hardes J, Hartwig E, Lehner B, Melcher I, Mutschler W, Schulte M, Tunn PU, Wozniak W, ZahltenHinguranage A, Zeifang F. Limb-salvage reconstruction with MUTARS hemipelvic endoprosthesis: a prospective multicenter study. Eur J Surg Oncol. 2009:35:1318-25.

55. Menendez LR, Ahlmann ER, Falkinstein Y, Allison DC. Periacetabular reconstruction with a new endoprosthesis. Clin Orthop Relat Res. 2009;467: 2831-7.

56. Fujiwara T, Ogura K, Kobayashi E, Tanzawa Y, Nakatani F, Chuman H, Kawai A. Clinical outcomes of surgical treatments for primary malignant bone tumors arising in the acetabulum. Sarcoma. 2015;2015:430576.

57. Kim HS, Kim KJ, Han I, Oh JH, Lee SH. The use of pasteurized autologous grafts for periacetabular reconstruction. Clin Orthop Relat Res. 2007:464:217-23.

58. Cottias P, Jeanrot C, Vinh TS, Tomeno B, Anract P. Complications and functional evaluation of 17 saddle prostheses for resection of periacetabular tumors. J Surg Oncol. 2001;78:90-100.

Ready to submit your research? Choose BMC and benefit from:

- fast, convenient online submission

- thorough peer review by experienced researchers in your field

- rapid publication on acceptance

- support for research data, including large and complex data types

- gold Open Access which fosters wider collaboration and increased citations

- maximum visibility for your research: over $100 \mathrm{M}$ website views per year

At $\mathrm{BMC}$, research is always in progress.

Learn more biomedcentral.com/submissions 